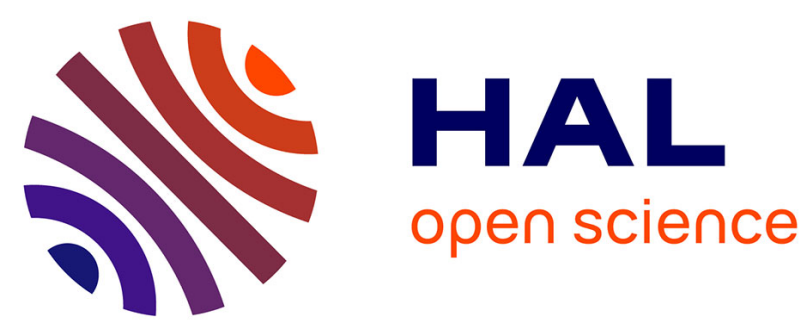

\title{
Outpatient Addiction Treatment for Problematic Alcohol Use: What Makes Patients Who Dropped Out Different from Those Who Did Not?
}

\author{
Vincent Wagner, Didier Acier, Jean-Eric Dietlin
}

\section{- To cite this version:}

Vincent Wagner, Didier Acier, Jean-Eric Dietlin. Outpatient Addiction Treatment for Problematic Alcohol Use: What Makes Patients Who Dropped Out Different from Those Who Did Not?. Substance Use and Misuse, 2018, pp.1 - 14. 10.1080/10826084.2018.1441310 . hal-01799729

\section{HAL Id: hal-01799729 \\ https://hal.science/hal-01799729}

Submitted on 25 May 2018

HAL is a multi-disciplinary open access archive for the deposit and dissemination of scientific research documents, whether they are published or not. The documents may come from teaching and research institutions in France or abroad, or from public or private research centers.
L'archive ouverte pluridisciplinaire HAL, est destinée au dépôt et à la diffusion de documents scientifiques de niveau recherche, publiés ou non, émanant des établissements d'enseignement et de recherche français ou étrangers, des laboratoires publics ou privés. 
This document is the preprint version of the published article in Substance Use \& Misuse. Final publication is available from Taylor \& Francis, publishers: https://doi.org/ $\underline{10.1080 / 10826084.2018 .1441310}$

Wagner, V., Acier, D., \& Dietlin, J.-E. (2018). Outpatient addiction treatment for problematic alcohol use: What makes patients who dropped out different from those who did not? Substance Use \& Misuse. 10.1080/10826084.2018.1441310 
Outpatient addiction treatment for problematic alcohol use: What makes patients who dropped out different from those who did not?

Vincent Wagner ${ }^{\mathrm{a}, \mathrm{b}, *}$, Didier Acier ${ }^{\mathrm{a}}$, and Jean-Eric Dietlin ${ }^{\mathrm{b}}$

${ }^{a}$ Department of Clinical Psychology, Laboratoire de Psychologie des Pays de la Loire, University of Nantes, Nantes, France

${ }^{\mathrm{b}}$ Beauséjour Addiction Care, Support and Prevention Center, Les Apsyades, Nantes, France

* Corresponding author at: Laboratoire de Psychologie des Pays de la Loire, Faculté de Psychologie, Université de Nantes, Chemin de la Censive-du-Tertre, BP 81227, 44312 Nantes Cedex 3, France

E-mail address: vincent.wagner@univ-nantes.fr

Running head: Dropouts from alcohol treatment

\section{Conflicts of Interest and Source of Funding}

None

\section{Acknowledgements}

We would like to thank the staff of the Beauséjour Addiction Care, Support and Prevention Center (ACSPC) for their time, information and assistance during this research and its parent study (Project DECA). We would like to thank as well outpatients who agreed to participate.

\section{Author contributions}


Vincent Wagner conducted literature searches, statistical analysis and wrote the first draft of the manuscript. Didier Acier wrote the main research protocol and got its approval by the ethical research committee. Jean-Eric Dietlin co-designed the research protocol and coordinated the study in Beauséjour Addiction Care, Support and Prevention Center. All authors contributed to and have approved the final manuscript. 


\section{Abstract}

Background: A minority of individuals with problematic alcohol use effectively seek help. Moreover, dropouts from care are not uncommon. It remains a major concern for health professionals, as adherence to treatment is significantly associated with better physical and psychological outcomes.

Objectives: The main aim of this research was to assess what factors could distinguish patients with problematic alcohol use who dropped out from those who did not.

Methods: The sample included 150 patients followed-up in an outpatient treatment center in France for a problematic alcohol use. Two measurement times were planned: at the first appointment and after six month of treatment. A large set of individual, environmental and institutional variables were considered to compare both subgroups.

Results: Patients who dropped out mostly differ from patients who did not with a higher level of alcohol-related problems, ambivalence, inclinations to use the substance, number of missed appointments. Significant results were also observed regarding a lower time gap between the first contact with the center and the first appointment, as well as the season of the last appointment.

Conclusions: Tailored motivational interventions could be offered to ambivalent patients, especially during the beginning of the treatment and some significant periods of the year. A particular focus should be brought on patients presenting such profiles in terms of level of alcohol problems, inclinations to drink and motivation to change. Overall, the study provides elements to better understand what may bring one patient to drop out of the treatment, and to improve the continuity of care. 


\section{Keywords}

Problematic alcohol use

Outpatients

Dropouts

Adherence to treatment

Retention 


\section{Introduction}

Problematic alcohol use

A report from the French Monitoring Centre for Drugs and Drug Addiction (Observatoire Français des Drogues et des Toxicomanies, OFDT) stated that in $2014,10 \%$ of people from 18 to 75 years old were using alcohol daily in France (Observatoire Français des Drogues et des Toxicomanies, 2015). Moreover, around 3.4 million of individuals were engaged in problematic alcohol drinking (i.e., abusers or dependent drinkers). This data is concerning especially when considering adverse effects of such consumption. Recent research noted that on the $535^{\prime} 000$ premature deaths occurred in France in 2009 , 49'000 could be related to direct and indirect effects of alcohol use (Guérin, Laplanche, Dunant, \& Hill, 2013). It represents almost $13 \%$ of premature deaths among men, $5 \%$ among women, and $22 \%$ among individuals from 15 to 24 . This prevalence is higher in France than in any other European countries (Britton et al., 2002; Corrao, 2002; Rehm, Taylor, Roerecke, \& Patra, 2007).

However, the literature highlights as well that only a minority of individuals with alcohol problematic use are effectively seeking help (Alonso et al., 2004; Probst, Manthey, Martinez, \& Rehm, 2015). According to the OFDT, in France, approximately $133^{\prime} 000$ problematic drinkers were treated in addiction-specialized treatment centers in 2014. Therefore, there is a significant gap between the estimated number of problematic drinkers and those finally received in care. Moreover, even if they complete their treatment, previous data showed that up to $83 \%$ of patients in France were likely to relapse within a 18 -month period after treatment (Malet et al., 2009). 
During the treatment itself, it is also not uncommon to observe dropouts from care (i.e., a patient leaving care before its commonly expected end). Previous results indicated that around $50 \%$ of patients in outpatient or inpatient addiction-treatment settings dropped out of care (Deane, Wootton, Hsu, \& Kelly, 2012; McHugh et al., 2013). It is a major concern for health professionals as adherence to treatment is significantly associated with an improvement in general health and well-being (Gossop, Stewart, Browne, \& Marsden, 2002; Perkins, Tharp, Ramsey, \& Patterson Adelv Unegv Waya), 2016). Some research tried to highlight important factors underlying this dropout process (Brorson, Ajo Arnevik, RandHendriksen, \& Duckert, 2013).

\section{Factors predicting dropout of addiction-specialized treatment}

One of the dimension most often associated with dropout likelihood is a younger age (Brorson et al., 2013; Perkins et al., 2016; Stevens et al., 2013; Vafaeinasab et al., 2015). Nonetheless, the role of many other sociodemographic factors (i.e., gender, education, marital status) remain under discussion (Brorson et al., 2013; López-Goñi, FernándezMontalvo, \& Arteaga, 2012; Smith et al., 2010; Vafaeinasab et al., 2015). On the contrary, in their review of 122 studies, Brorson et al. (2013) highlighted the rather consistent negative influence of cognitive deficits on retention rates. These impairments are frequent in psychoactive substance users and can affect a large set of cognitive functions: problem resolution, learning, memory, etc. Previous research stated that cognitive impairments could act on care efficacy, treatment outcomes or substance use during treatment (Aharonovich, Nunes, \& Hasin, 2003; Likhitsathian et al., 2012; Marceau, Lunn, Berry, Kelly, \& Solowij, 2016). However, the impact of many other substance-related or personal factors remain inconsistent across study settings, samples or methods, such as the use of a specific substance, co-occurring mental disorders (with the exception of anti-social and histrionic personality 
disorders) (Brorson et al., 2013; López-Goñi et al., 2012; Meier \& Barrowclough, 2009). In particular, the influence of psychiatric comorbidities on retention in treatment appears to be particularly controversial. Overall, these disorders are often associated with worse treatment outcomes and less time in care (Darke et al., 2009; González-Saiz, Vergara-Moragues, VerdejoGarcía, Fernández-Calderón, \& Lozano, 2014). However, there is some evidence that dual diagnosis is associated with better outcomes following treatment as well as long-term retention in treatment (Maremmani et al., 2013). Other studies also stated that this condition may have no significant effect on dropouts (see for instance, Astals et al., 2009). It is also possible that some psychopathological traits or symptomatology could lead to a very specific set of outcomes (Maremmani et al., 2016). Dual diagnosis remains relevant to investigate, as it is a frequent situation in substance users and can represent a significant factor in the development and maintenance of alcohol misuse (Roncero et al., 2015; van Emmerik-van Oortmerssen et al., 2014).

Along with the examination of the substance used, another useful dimension is the severity of problems associated with this consumption. Indeed, there is evidence that a higher level of use and misuse, was associated with a reduced retention and attendance in treatment (Skule et al., 2017). Other authors found that it is a lower severity of alcohol dependence which was related to dropout likelihood (Ray, Hutchison, \& Bryan, 2006; Vuoristo-Myllys, Lahti, Alho, \& Julkunen, 2013). However, rather than solely considering the intensity of the substance use disorder, one could also evaluate to what extent the quality of the individual's physical, psychological and social life is adversely affected when entering in treatment and how it can hamper treatment retention (Daeppen et al., 2014; Picci et al., 2014). In that sense, health-related quality of life is often used as an indicator of substance use consequences and 
treatment-induced changes (Daeppen et al., 2014; Johnson et al., 2008; Luquiens, Reynaud, Falissard, \& Aubin, 2012).

Additionally, craving, as a conscious expression of desire directed toward the use a substance (Tiffany \& Wray, 2012), is a key factor when studying patterns of substance use and trajectory in care (Morgenstern, DiFranza, Wellman, Sargent, \& Hanewinkel, 2016; Witkiewitz, 2011). Alcohol urges are known to take a variety of form and intensity, and are particularly unpredictable for the user (Kvamme, Asplund, \& Bjerke, 2015). The most intense experiences of craving can overwhelm any intention to change (Bradshaw, Shumway, Wang, \& Harris, 2014; Browne, Wray, Stappenbeck, Krenek, \& Simpson, 2016). Once again, the role of this factor on treatment dropouts remains unclear. In some studies, urges to drink can significantly predict early dropouts (Field, Mogg, Mann, Bennett, \& Bradley, 2013; Ray et al., 2006), but not in others (Deane et al., 2012; Filho \& Baltieri, 2012).

Motivation to change is also an interesting personal-related dimension related to the trajectory in care of problematic drinkers (Collins, Malone, \& Larimer, 2012; Rice, Hagler, \& Tonigan, 2014). It refers to a multidimensional dynamic process describing the individual disposition for behavioral and psychological change (Arkowitz, Westra, Miller, \& Rollnick, 2007; Prochaska, DiClemente, \& Norcross, 1992). However, the literature is rather inconsistent with studies suggesting that either lower or higher motivation to change could be related to higher drop-out risks, while for other research, there is no significant association (Brorson et al., 2013; Callaghan et al., 2005; Kelly, Urbanoski, Hoeppner, \& Slaymaker, 2012).

Some authors also noted that treatment-related variables and processes (e.g., treatment duration, setting, satisfaction, alliance or therapist characteristics) could be among the most significant predictors of treatment completion, but strong evidence of this association is still lacking (Brorson et al., 2013; Curran, Stecker, Han, \& Booth, 2009). They 
could indeed act as treatment-related barriers (i.e., external elements which hinder the care process; Allen, 1994) or facilitators of retention in treatment (Saunders, Zygowicz, \& D'Angelo, 2006). Barriers and facilitators can affect the mere initiation of the care process, as well as the later retention and adherence in treatment (Saunders et al., 2006). Simultaneously, the actual relevance of the place where patients are referred, for instance an outpatient or an inpatient settings, when they come from other health-, social-, or judicial facilities, cannot be ignored (Mulder, Koopmans, \& Hengeveld, 2005; Roncero et al., 2012).

Finally, a growing number of studies highlights the relationship between time perspective and substance use (Beenstock, Adams, \& White, 2011; Cole, Andretta, \& McKay, 2016). This dimension refers to a relatively stable disposition which guides how an individual considers and acts regarding his past, present and future (Adamson, Sellman, \& Frampton, 2009; Zimbardo \& Boyd, 1999). This particular disposition impacts the person's goals and actions (Henson, Carey, Carey, \& Maisto, 2006). For instance, a future orientation implies goal planning and consideration of future consequences of current behaviors. As individuals with future-related perspective would be more likely to engage themselves in healthy behaviors (Beenstock et al., 2011), we could then assume that the patient time perspectives are able to influence his own engagement and adherence in treatment.

Aims of this research

Even though researchers tried to better understand dropout from addiction treatment, one must admit that these data are often contradictory. Moreover, clinicians sometimes have their own explanations on these dropouts, but not always supported by empirical data. Therefore, the main aim of this exploratory research is to further contribute to the current knowledge on dropout from addiction-specialized treatment. Based on the previous literature and on discussion with local stakeholders, we chose to include a comprehensive set of both 
well and sparsely studied indicators to see if they were able to distinguish patients who dropped out of an outpatient addiction treatment center from those who did not. These indicators include: socio-demographic characteristics (gender, age, education, professional status, socio-professional category, financial resources, housing), alcohol- (frequency of use, polydrug use, level of severity of alcohol-related problems, inclinations to use or not to use alcohol), treatment-related (source of the initial demand, obligation from the court, interventions, motivation to change, barriers to treatment) variables, health-related quality of life, time perspectives and cognitive impairments.

\section{Methods}

Setting

The present research took place in an outpatient treatment center in France. The care mostly consists in individual consultations with one or several stakeholders in parallel (i.e., addictologist physician, psychiatrist, psychologist, or social worker), with various frequencies of appointments: from once a month to once a week. Depending on the clinical situation, familial and marital interventions, as well as recreational workshops, can be offered. Several inclusion criteria were used: (i) adult (i.e., aged over 18), (ii) problematic alcohol use as main issue, (iii) first visit to the center, (iv) good knowledge of spoken and written French, (v) has given his or her written informed consent. Exclusion criteria were: (i) problematic drug use as main issue, (ii) adult under court-established guardianship or tutorship, (iii) higher cognitive functions disorder, (iv) major co-occurring mental disorder (e.g., massive depressive disorder, psychotic disorders). At their first appointment, patients were informed about the study and were proposed to participate. If they gave their written consent, they were given a set of questionnaires to fill, helped if needed by a member of the clinical staff. After six months of 
follow-up in the center, participants filled the same set of questionnaires again. The Protection to Persons Committee OUEST IV - Nantes, a local independent research committee, reviewed and approved the research protocol (OR/BB CPP N883/2014; Project DECA - n²014-A0071740 - "Assessment of change at six-month follow-up of patients in an addiction outpatient treatment facility"). This study was also declared to the French Data Protection Authority (CNIL, declaration receipt $\left.n^{\circ} 1775023\right)$.

\section{Participants}

Between November 2014 and January 2016, 299 new patients contacted the center for a problematic substance use. Among them, 256 demands were eligible for the Project DECA (i.e., $85.6 \%$ of total demands). Main reason for ineligibility was associated with a demand unrelated to alcohol misuse (e.g., cannabis, gambling, tobacco or codeine misuse). 152 patients accepted to take part in the study. Other patients $(n=104)$ mainly refused or were absent for their first appointment. There were no significant differences regarding their sociodemographic characteristics between the final sample and patients who did not want to participate. Two participants were removed at this stage because of a large number of missing answers. After six months of follow-up, 69 patients (46\% of the initial sample) were considered as dropouts. The decision to categorize patients as dropouts is traditionally made by the clinical team when a patient does not come to a scheduled appointment and that he does not return to resume the follow-up.

\section{Measures}

We used participants' answers to (i) a clinical summary sheet gathering several sociodemographic, substance- and treatment-related data, (ii) the Alcohol Use Disorders Identification Test (Babor, Higgins-Biddle, Saunders, \& Monteiro, 2001; Gache et al., 2005) (iii) 
a French version of the Stages of Change Readiness and Treatment Eagerness Scale-8A (SOCRATES) (Miller \& Tonigan, 1996) (iv) a French version of the Approach and Avoidance of Alcohol Questionnaire (AAAQ) (McEvoy, Stritzke, French, Lang, \& Ketterman, 2004) (v) the MOntreal Cognitive Assessment (MOCA) (Nasreddine et al., 2005) (vi) the Medical Outcome Study Short Form-36 items health survey (MOS-SF-36) (Leplège, Ecosse, Coste, Pouchot, \& Perneger, 2001; Ware \& Sherbourne, 1992) (vii) a French adaptation of the Barriers to Treatment Inventory (BTI) (Rapp et al., 2006) and (viii) the Zimbardo Time Perspective Inventory (ZTPI) (Loose, Acier, Pilet, \& Sysaykeo, 2017; Zimbardo \& Boyd, 1999).

Prior to that, three members of the research team performed the translation of questionnaires unavailable in French (i.e., SOCRATES, AAAQ and BTI). Each draft was discussed as long as there was not an agreement between team members. Respect of the original meaning of labels was an important rule. Common versions were then revised by an external bilingual person and were back-translated in English.

\section{Statistical analysis}

Statistical analyses sought to compare patients who dropped out and those who did not. For the purpose of this study, only baseline data were used. According to the study objectives, a large set of variables was considered: socio-demographic characteristics (age, gender, education, professional status, socio-professional category, financial resources, housing), treatment- (source of the demand for care, obligation from the court, interventions and substance-related variables (e.g., frequency of use, polydrug use, previous experiences of care), level of alcohol use problems (i.e., AUDIT), inclinations to use or not alcohol (AAAQ), motivation to change (SOCRATES), cognitive impairment (MOCA), health-related quality of life (SF-36), barriers to treatment (BTI) and time perspectives (ZTPI). Comparisons on our unequal 
subsamples were conducted using, where applicable, $\chi^{2}$ test or the Tukey-Kramer method, which aims to control for the family-wise error rate (Montgomery, 2012).

\section{Results}

Patients' demographics

At the first measurement time, the mean age of the sample was 45.01 years $(S D=$ 11.21). Among the 150 participants, $74.0 \%$ were men $(n=111), 66.7 \%$ were employees or factory workers, and almost the same number of participants received at least 12 years of education (51.3\%) than those who did not (48.7\%). At their entry in treatment, $66.7 \%$ of the sample stated that they had been using alcohol four times a week or more. The mean score at the Alcohol Use Disorders Identification Test (AUDIT) was $21.47(S D=8.08)$, well above the cut-off score of 7 indicating a problematic use of alcohol (Gache et al., 2005). Table 1 provides full characteristics of the sample.

(Insert Table 1 here)

Overview of dropouts

Overall, 745 interventions were carried out within the follow-up period ( $M=4.97 ; S D$ $=2.79)$. Unsurprisingly, patients who dropped out had a lower length of treatment $(M=54.74$ days; $S D=51.82$ versus $M=194.83$ days; $S D=30.09$, Tukey-Kramer's $q=29.1, p<.001)$. A fortiori, they less often met health professionals: $M=3.06$ appointments; $S D=1.95 ;$ Min $=1$; $\operatorname{Max}=9$ versus $M=6.59$ appointments; $S D=2.33, \operatorname{Min}=1 ; \operatorname{Max}=9, q=14.1, p<.001$. Patients who dropped out received significantly fewer individual consultations $(M=2.97 ; S D=1.97)$ than those who did not $(M=6.26 ; S D=1.82, q=15, p<.001)$. No differences could be found regarding other interventions. 
Among dropouts, 48 patients (69.6\%) left the care without notifying stakeholders. Eleven patients openly said that they wanted to interrupt the treatment, for various reasons (e.g., the care did not seem useful any more for them). Other specific reasons appeared as well: death $(n=2 ; 2.9 \%)$, reorientation or relocation $(n=7 ; 10.1 \%)$ and imprisonment $(n=1$; $1.4 \%)$.

Socio-demographic and substance-related variables

None of the socio-demographic variables could distinguish patients who dropped out from those who remained in care (see Table 2 for full details). On the contrary, the level of alcohol problems, measured via the global AUDIT score, could highlight a difference. Patients who dropped out present a slightly higher score $(M=23.14 ; S D=6.99)$ than patients who stayed in treatment $(M=20.04 ; S D=8.69 ; q=3.36, p<.05)$. However, other substance-related variables do not distinguish the two groups: alcohol use frequency, previous experience of care for the same disorder, poly-drug use, etc. Table 3 provides all results regarding these variables.

(Insert Table 2 here)

(Insert Table 3 here)

Treatment-related variables, inclinations to use alcohol and ambivalence

Analyses revealed differences between dropouts and patients remaining in care regarding some treatment-related variables. First, those who dropped out missed significantly more appointments during their follow-up ( $M=1.96$ missed appointments; $S D=1.47$ versus $M=1.02 ; S D=1.45, q=5.56, p<.001)$. Moreover, this result is not found regarding cancelled appointments (e.g., the patient calls the center to warn that he will not be able to attend the 
next appointment). Another surprising fact is that the difference in days between the first contact with the center and the first appointment is lower in dropouts than in other patients $(M=27.30$ days; $S D=13.64$ versus $M=35.60$ days; $S D=21.96, q=3.85, p<.01)$. We noticed as well that there were significantly more dropouts during fall (i.e., September to November) and even more during winter (i.e., December to February) seasons $\left(\chi^{2}(3)=10.97, p<.05\right)$. Specifically, among the 69 patients who dropped out, 19 (27.5\%) and $26(37.7 \%)$ left the follow-up during these seasons. No other treatment-related variables had a significant role. The Table 4 summarizes these data.

(Insert Table 4)

At last, among all questionnaires administrated to patients, only three subscales showed significant effects. Precisely, it involves two of the AAAQ subscales (i.e., Obsessed/Compelled and Inclined/Indulgent) and the Ambivalence subscale of the SOCRATES. Dropouts patients had a higher score on the Inclined/Indulgent $(M=5.04 ; S D=2.19$ versus $M$ $=3.96 ; S D=2.42, q=3.96, p<.01)$, Obsessed $/$ Compelled $(M=4.44 ; S D=2.28$ versus $M=3.68$; $S D=2.38 ; q=2.81, p<.05)$ and Ambivalence subscales $(M=16.94 ; S D=2.68$ versus $M=15.27$; $S D=3.69 ; q=4.42 ; p<.01)$. The last table, Table 5 , provides full details on these results.

(Insert Table 5 here)

\section{Discussion}

Results interpretation

This study aimed to better understand addiction treatment dropouts. Here, 69 patients (46\% of the total sample) dropped out during the six-month follow-up period. Regarding the recent literature on similar settings, this proportion of dropout is relatively normal (Roncero et al., 2012; Vuoristo-Myllys et al., 2013). Analyses carried out in this research included a large 
set of individual, social, treatment or substance-related variables. In the end, only a few of these variables were effectively able to distinguish patients who dropped out and those who did not. Nonetheless, even if they are surprising in light of other research, non-significant results remain important for clinicians and researchers who witness such treatment trajectories. Indeed, several studies highlighted that clinicians were mainly explaining dropouts with client-related variables, whereas patients emphasized issues regarding social support and staff relationships (Palmer, Murphy, Piselli, \& Ball, 2009).

However, some non-significant results need to be further discussed. For instance, past literature identified that age, ethnicity, gender or employment were sometimes able to predict retention or dropout of patients (Braitman \& Kelley, 2016; Graff et al., 2009; McCaul, Svikis, \& Moore, 2001) whereas these findings were not replicated here. It has to be noted that previous studies mostly used regression models to predict treatment retention, instead of comparing patients who did drop out and those who stayed in care. Some samples were also more heterogeneous than ours regarding substance use: alcohol only versus various substance (Braitman \& Kelley, 2016; McCaul et al., 2001).

Moreover, given the chosen inclusion and exclusion criteria, some additional indicators could not distinguish dropouts and patients remaining in treatment. For example, MOCA scores only have a short range, as presenting higher cognitive dysfunctions was an exclusion criterion. Consequently, influence of cognitive deficits may be poorly judged here, whereas the literature suggests that this dimension is one the most consistent risk factor for addiction treatment dropout (Aharonovich et al., 2003; Brorson et al., 2013). The same consideration could be brought to co-occurring mental health problems, even if past research is more contradictory regarding its impact on dropout (Meier \& Barrowclough, 2009). 
Nonetheless, patients who dropped out present a higher level of severity of their alcohol-related problems, as measured via the AUDIT. They appear as well more ambivalent regarding their intention to change, as suggested by the score of the Ambivalence subscale of the SOCRATES. Moreover, these patients had a higher score on the overall approach inclination to use alcohol from the AAAQ. It has to be noted that this scale distinguish, respectively, a strong craving-like urge to drink (the Obsessed/Compelled subscale) and a subtler desire to drink generally conditioned by social and context incentives to use alcohol (the Inclined/Indulgent subscale). Therefore, patients who dropped out may feel a more intense craving and are particularly sensitive to social and contextual incentives for alcohol consumption. The articulation between these dimensions, often retrieved in the literature, is interesting to better grasp underlying processes at stake in patients.

There is evidence in the literature that avoidance inclination (i.e., inclination not to use alcohol, covering a large set of behaviors and intentions, as measured by the Resolved/Regulated subscale of the AAAQ) may moderate effects of approach inclination on drinking behavior, especially during initiation of treatment (Schlauch et al., 2013). Moreover, conflict between high levels of approach and avoidance inclinations may lead to ambivalence, an unstable state regarding motivation to use or not to use alcohol. Thus, it is not so surprising that an ambivalent patient regarding his substance consumption will miss more appointments, before eventually even leaving the care. Moreover, it is also relevant to consider that this outpatient setting may not be relevant, at first, for all patients (Roncero et al., 2012). Especially, extrinsic motivation for care can be quite common for patients who are referred from other facilities, or are under the pressure of their significant others (Wagner et al., 2017). A specific attention is required regarding specific needs, resources, including the 
individual motivation, and difficulties of the patient before and during the actual referral process.

Then, patients who dropped out had waited less time between the date they first contacted the center and the date they had their first appointment. This fact remains somewhat unsettling. One may assume that those who wait longer and still turn up for their appointment have higher motivation and ongoing needs. However, we may also suggest that some sort of latency period may be needed to better define and incorporate the need for change, especially for the more ambivalent patients. However, this process could be quite uncertain and some patients may not even come for the beginning of the follow-up. Indeed, according to substance users, being on a waiting list seems to be a significant barrier to enter treatment (Appel, Ellison, Jansky, \& Oldak, 2004; Redko, Rapp, \& Carlson, 2006). Many patients become less interested to be involved in treatment after being forced to wait for a relatively long period (Brown, Hickey, Chung, Craig, \& Jaffe, 2009). Moreover, it is now long known that waiting time preceding the actual treatment entry does not involve noticeable change regarding substance use pattern (Best et al., 2002). However, we could consider implementing brief interventions to invest the time the patient will need to wait before the actual first appointment, to improve the later treatment linkage and retention. These interventions could focus on self-awareness and self-management, while informing patients about upcoming treatment and the overall change process. An interesting way to reach patients during this period could be to use mobile-, Internet-applications, or emails.

Finally, we found a rather original finding, related to the season of the last appointment before the dropout. Precisely, the majority of dropouts happened in fall and even more in winter, around the end of the year. This later period is characterized by holiday season, which 
involves lots of solicitations to drink alcohol, especially in France. One may assume that these events, for instance Christmas and New Year Eve parties, would also be significant in other European, or even all Western, countries, given their shared culture and history. However, the situation might be quite different in other distant countries. Indeed, if the Western cultural influence is now broadly disseminated around the world, different cultures still coexist, with their own calendar of major social and/or religious events. However, in the current situation, it is also true that many patients initiate their care in fall (i.e., $40.7 \%$ of those remaining in care and $53.6 \%$ of those who dropped out). As those who left prematurely their follow-up spent approximately 55 days in treatment, it may explain a greater number of dropouts in winter. Nonetheless, the end of the year remains a critical moment for patients in treatment. What is here important to highlight is the relevance of these events on the alcohol use patterns and the treatment course (Alcohol and Public Policy Group, 2010).

According to our findings, we suggest that tailored motivational interventions may be helpful for ambivalent patients in order to reduce their approach inclination of alcohol rather than solely enhance avoidance inclination, especially at the beginning of treatment (Spruyt et al., 2013). The literature stated that being focused on persistent restrictive and/or avoiding strategies of alcohol use would be detrimental for the patients, as they may not be able, at early stages of change, to manage underlying emotional conflicts associated with alcohol use (Schlauch, Christensen, Derrick, Crane, \& Collins, 2015; Spruyt et al., 2013). These interventions could be useful as well to manage critical periods of the year. As defined in the literature, brief motivational interventions, early provided in the follow-up, is a significant tool to improve the patient's motivation to change. Furthermore, several studies highlighted how receiving a motivational program could lead to a higher likelihood of long-term retention in treatment (Bachiller et al., 2015; Santa Ana, Wulfert, \& Nietert, 2007). We also assume that 
there is a true need to work with the patient on his cognitions and his expectations regarding retention in treatment and changes in the substance use.

Overall, a specific focus should be brought on patients presenting particular profiles in terms of severity of alcohol problems, inclinations to drink and motivation to change. In any case, evaluation of the two latest dimensions should systematically be conducted (Csillik \& Petot, 2012). Last, given the brevity of the follow-up of patients who dropped out, one may wonder whether the treatment should be focused on the improvement of the adherence to treatment (i.e., identifying patient expectations, needs and difficulties), and/or on a short but efficient management of the substance use disorder.

\section{Limits}

This study has limits. First, answers from patients can be influenced by their initial motivation to be in care. Similarly, these 150 participants took part in the research protocol while they were simultaneously in treatment. Therefore, it may be possible that their characteristics are somewhat different from those of the 104 patients who explicitly did not want to participate, were absent or were excluded. Furthermore, this study was conducted on a single site. Therefore, it may limit the generalization of results to very different addiction treatment centers or programs. Third, the study used several questionnaires translated in French but not currently validated in this language. Fourth, no standardized alcohol treatment was given. Indeed, frequency of visits and interventions were vastly depending on individual needs. Although this is clinically sound, it can make group comparisons quite difficult. Moreover, we did not have a reliable description of psychopharmacological treatments received by each patient, whereas it could represent a significant factor of retention or dropout. Last, age of onset and length of alcohol misuse were not consistently assessed in this sample, therefore not included in the analyses. 


\section{Conclusions}

Initially, this study searched to answer a real clinical inquiry: Why do patients with problematic alcohol use drop out? Current results highlight the initiation and adherence of alcohol-specialized outpatient treatment in France. Overall, the study provides elements which can provide a better understanding of the dropout phenomenon. Indeed, patients who left the care differ significantly from other patients by a higher severity of their alcohol-related problems, ambivalence, inclinations to use alcohol, and their number of missed appointments. They also waited less time before receiving their first appointment. Last, most dropouts occurred in fall and especially in winter. By extension, these data could be relevant for practitioners to improve the continuity of care. By taking into account the specific needs and difficulties of this population of patients, one may help them to better define their own expectations regarding the process of care and to be more involved in the treatment. Research on this topic must be continued, for instance, by contacting patients who dropped out to assess what made them leave their follow-up.

\section{Funding:}

This research did not receive any specific grant from funding agencies in the public, commercial, or not-for-profit sectors.

\section{Declaration of interest}

The authors report no conflicts of interest. The authors alone are responsible for the content and writing of the paper.

\section{References}

Adamson, S. J., Sellman, J. D., \& Frampton, C. M. A. (2009). Patient predictors of alcohol treatment outcome: A systematic review. Journal of Substance Abuse Treatment, 36(1), 75-86. https://doi.org/10.1016/j.jsat.2008.05.007 
Aharonovich, E., Nunes, E., \& Hasin, D. (2003). Cognitive impairment, retention and abstinence among cocaine abusers in cognitive-behavioral treatment. Drug and Alcohol Dependence, 71(2), 207-211.

Alcohol and Public Policy Group. (2010). Alcohol: No Ordinary Commodity - a summary of the second edition. Addiction, 105(5), 769-779. https://doi.org/10.1111/j.13600443.2010.02945.x

Allen, K. (1994). Development of an instrument to identify barriers to treatment for addicted women, from their perspective. International Journal of the Addictions, 29(4), 429444.

Alonso, J., Angermeyer, M. C., Bernert, S., Bruffaerts, R., Brugha, T. S., Bryson, H., ... ESEMeD/MHEDEA 2000 Investigators, European Study of the Epidemiology of Mental Disorders (ESEMeD) Project. (2004). Use of mental health services in Europe: results from the European Study of the Epidemiology of Mental Disorders (ESEMeD) project. Acta Psychiatrica Scandinavica. Supplementum, (420), 47-54. https://doi.org/10.1111/j.1600-0047.2004.00330.x

Appel, P. W., Ellison, A. A., Jansky, H. K., \& Oldak, R. (2004). Barriers to enrollment in drug abuse treatment and suggestions for reducing them : Opinions of drug injecting street outreach clients and other system stakeholders. American Journal of Drug and Alcohol Abuse, 30(1), 129-153. https://doi.org/10.1081/ADA-120029870

Arkowitz, H., Westra, H. A., Miller, W. R., \& Rollnick, S. (Éd.). (2007). Motivational Interviewing in the Treatment of Psychological Problems (1st Ed). New York: The Guilford Press.

Astals, M., Díaz, L., Domingo-Salvany, A., Martín-Santos, R., Bulbena, A., \& Torrens, M. (2009). Impact of Co-Occurring Psychiatric Disorders on Retention in a Methadone Maintenance Program: An 18-Month Follow-Up Study. International Journal of 
Environmental Research and Public Health, 6(11), 2822-2832. https://doi.org/10.3390/ijerph6112822

Babor, T. F., Higgins-Biddle, J. C., Saunders, J. B., \& Monteiro, M. (2001). AUDIT. The Alcohol Use Disorders Identification Test. Guidelines for use in primary health care. (2nd edition). Geneva, Switzerland: World Health Organization.

Bachiller, D., Grau-López, L., Barral, C., Daigre, C., Alberich, C., Rodríguez-Cintas, L., ... Roncero, C. (2015). Motivational interviewing group at inpatient detoxification, its influence in maintaining abstinence and treatment retention after discharge. Adicciones, 27, 109118.

Beenstock, J., Adams, J., \& White, M. (2011). The association between time perspective and alcohol consumption in university students: cross-sectional study. The European Journal of Public Health, 21(4), 438-443. https://doi.org/10.1093/eurpub/ckp225

Best, D., Noble, A., Ridge, G., Gossop, M., Farrell, M., \& Strang, J. (2002). The relative impact of waiting time and treatment entry on drug and alcohol use. Addiction Biology, 7(1), 67-74. https://doi.org/10.1080/135562101200100607

Bradshaw, S. D., Shumway, S. T., Wang, E. W., \& Harris, K. S. (2014). Addiction and the Mediation of Hope on Craving, Readiness, and Coping. Journal of Groups in Addiction \& Recovery, 9(4), 294-312.

Braitman, A. L., \& Kelley, M. L. (2016). Initiation and retention in couples outpatient treatment for parents with drug and alcohol use disorders. Experimental and Clinical Psychopharmacology, 24(3), 174-184. https://doi.org/10.1037/pha0000072

Britton, A., Nolte, E., White, I. R., Grønbæk, M., Powles, J., Cavallo, F., \& McPherson, K. (2002). A comparison of the alcohol-attributable mortality in four European countries. 
$\begin{array}{llll}\text { European Journal of } & \text { Epidemiology, } & \text { 643-652. }\end{array}$ https://doi.org/10.1023/A:1024834608689

Brorson, H. H., Ajo Arnevik, E., Rand-Hendriksen, K., \& Duckert, F. (2013). Drop-out from addiction treatment: A systematic review of risk factors. Clinical Psychology Review, 33(8), 1010-1024. https://doi.org/10.1016/j.cpr.2013.07.007

Brown, B. S., Hickey, J. E., Chung, A. S., Craig, R. D., \& Jaffe, J. H. (2009). The Functioning of Individuals on a Drug Abuse Treatment Waiting List. The American Journal of Drug and Alcohol Abuse, 15, 261-274. https://doi.org/10.3109/00952998908993407

Browne, K. C., Wray, T. B., Stappenbeck, C. A., Krenek, M., \& Simpson, T. L. (2016). Alcohol Consumption, Craving, and Craving Control Efforts Assessed Daily in the Context of Readiness to Change Among Individuals with Alcohol Dependence and PTSD. Journal of Substance Abuse Treatment, 61, 34-41. https://doi.org/10.1016/j.jsat.2015.09.005

Callaghan, R. C., Hathaway, A., Cunningham, J. A., Vettese, L. C., Wyatt, S., \& Taylor, L. (2005). Does stage-of-change predict dropout in a culturally diverse sample of adolescents admitted to inpatient substance-abuse treatment? A test of the Transtheoretical $\begin{array}{llll}\text { Model. } & \text { Addictive } & \text { Behaviors, } & \text { 30(9), }\end{array}$ https://doi.org/10.1016/j.addbeh.2005.07.015

Cole, J. C., Andretta, J. R., \& McKay, M. T. (2016). The relationship between temporal profiles and alcohol-related problems in University undergraduates: Results from the United $\begin{array}{lll}\text { Kingdom. } & \text { Addictive } & \text { Behaviors, }\end{array}$ https://doi.org/10.1016/j.addbeh.2015.12.001

Collins, S. E., Malone, D. K., \& Larimer, M. E. (2012). Motivation to change and treatment attendance as predictors of alcohol-use outcomes among project-based Housing First 
residents.

Addictive

Behaviors,

$37(8)$

931-939.

https://doi.org/10.1016/j.addbeh.2012.03.029

Corrao, G. (2002). Alcohol-attributable and alcohol-preventable mortality in Italy: A balance in 1983 and 1996. The European Journal of Public Health, 12(3), 214-223. https://doi.org/10.1093/eurpub/12.3.214

Csillik, A. S., \& Petot, J.-M. (2012). L'évaluation des stades de changement dans les addictions. L'Évolution Psychiatrique, $77(3)$, $331-341$. https://doi.org/10.1016/j.evopsy.2012.02.002

Curran, G. M., Stecker, T., Han, X., \& Booth, B. M. (2009). Individual and Program Predictors of Attrition from VA Substance Use Treatment. The Journal of Behavioral Health Services \& Research, 36(1), 25-34. https://doi.org/10.1007/s11414-007-9093-z

Daeppen, J.-B., Faouzi, M., Sanchez, N., Rahhali, N., Bineau, S., \& Bertholet, N. (2014). Quality of Life Depends on the Drinking Pattern in Alcohol-Dependent Patients. Alcohol and Alcoholism, 49(4), 457-465. https://doi.org/10.1093/alcalc/agu027

Darke, S., Mills, K., Teesson, M., Ross, J., Williamson, A., \& Havard, A. (2009). Patterns of major depression and drug-related problems amongst heroin users across 36 months. Psychiatry Research, 166(1), 7-14. https://doi.org/10.1016/j.psychres.2007.12.007

Deane, F., Wootton, D., Hsu, C.-L., \& Kelly, P. (2012). Predicting dropout in the first 3 months of 12-step residential drug and alcohol treatment in an Australian sample. Faculty of Health and Behavioural Sciences - Papers (Archive), 216-225.

Field, M., Mogg, K., Mann, B., Bennett, G. A., \& Bradley, B. P. (2013). Attentional biases in abstinent alcoholics and their association with craving. Psychology of Addictive Behaviors, 27(1), 71-80. https://doi.org/10.1037/a0029626 
Filho, J. M. C., \& Baltieri, D. A. (2012). Psychosocial and Clinical Predictors of Retention in Outpatient Alcoholism Treatment. Revista Brasileira de Psiquiatria, 34(4), 413-421. https://doi.org/10.1016/j.rbp.2012.03.003

Gache, P., Michaud, P., Landry, U., Accietto, C., Arfaoui, S., Wenger, O., \& Daeppen, J.-B. (2005). The Alcohol Use Disorders Identification Test (AUDIT) as a Screening Tool for Excessive Drinking in Primary Care: Reliability and Validity of a French Version: Alcoholism: Clinical \& Experimental Research, 29(11), 2001-2007. https://doi.org/10.1097/01.alc.0000187034.58955.64

González-Saiz, F., Vergara-Moragues, E., Verdejo-García, A., Fernández-Calderón, F., \& Lozano, O. M. (2014). Impact of Psychiatric Comorbidity on the In-Treatment Outcomes of Cocaine-Dependent Patients in Therapeutic Communities. Substance Abuse, 35(2), 133 -140. https://doi.org/10.1080/08897077.2013.812544

Gossop, M., Stewart, D., Browne, N., \& Marsden, J. (2002). Factors associated with abstinence, lapse or relapse to heroin use after residential treatment: protective effect of coping responses. Addiction (Abingdon, England), 97(10), 1259-1267.

Graff, F. S., Morgan, T. J., Epstein, E. E., McCrady, B. S., Cook, S. M., Jensen, N. K., \& Kelly, S. (2009). Engagement and Retention in Outpatient Alcoholism Treatment for Women. American Journal on Addictions, 18(4), 277-288. https://doi.org/10.1080/10550490902925540

Guérin, S., Laplanche, A., Dunant, A., \& Hill, C. (2013). Alcohol-attributable mortality in France. The European Journal of Public Health, ckt015. https://doi.org/10.1093/eurpub/ckt015

Henson, J. M., Carey, M. P., Carey, K. B., \& Maisto, S. A. (2006). Associations Among Health Behaviors and Time Perspective in Young Adults: Model Testing with Boot-Strapping 
Replication. Journal of Behavioral Medicine, 29(2), 127-137. https://doi.org/10.1007/s10865-005-9027-2

Johnson, B. A., Rosenthal, N., Capece, J., Wiegand, F., Mao, L., Beyers, K., ... Topiramate for Alcohol Study Group. (2008). Improvement of Physical Health and Quality of Life of Alcohol-Dependent Individuals With Topiramate Treatment\&It;subtitle\&gt;US Multisite Randomized Controlled Trial\&It;/subtitle\&gt; Archives of Internal Medicine, 168(11), 1188. https://doi.org/10.1001/archinte.168.11.1188

Kelly, J. F., Urbanoski, K. A., Hoeppner, B. B., \& Slaymaker, V. (2012). « Ready, willing, and (not) able " to change: young adults' response to residential treatment. Drug and Alcohol Dependence, 121(3), 224-230. https://doi.org/10.1016/j.drugalcdep.2011.09.003

Kvamme, B. O., Asplund, K., \& Bjerke, T. N. (2015). Drinking resumption: problematic alcohol use relapse after rehabilitation. A phenomenological hermeneutical perspective. Scandinavian Journal of Caring Sciences, 29(4), 716-723. https://doi.org/10.1111/scs.12202

Leplège, A., Ecosse, E., Coste, J., Pouchot, J., \& Perneger, T. (2001). Le questionnaire MOS SF36: manuel de l'utilisateur et guide d'interprétation des scores. Editions Estem.

Likhitsathian, S., Saengcharnchai, P., Uttawichai, K., Yingwiwattanapong, J., Wittayanookulluk, A., \& Srisurapanont, M. (2012). Cognitive changes in topiramate-treated patients with alcoholism: A 12-week prospective study in patients recently detoxified: Cognition, topiramate and alcohol. Psychiatry and Clinical Neurosciences, 66(3), 235-241. https://doi.org/10.1111/j.1440-1819.2012.02326.x

Loose, T., Acier, D., Pilet, J.-L., \& Sysaykeo, J. (2017). La temporalité. Un facteur déterminant des conduites addictives. Alcoologie et Addictologie, 39(2), 111-119. 
López-Goñi, J. J., Fernández-Montalvo, J., \& Arteaga, A. (2012). Addiction Treatment Dropout: Exploring Patients' Characteristics: Treatment Dropout in Addictions. The American Journal on Addictions, 21(1), 78-85. https://doi.org/10.1111/j.15210391.2011.00188.x

Luquiens, A., Reynaud, M., Falissard, B., \& Aubin, H. J. (2012). Quality of life among alcoholdependent patients: How satisfactory are the available instruments? A systematic review. Drug and Alcohol Dependence, 125(3), 192-202. https://doi.org/10.1016/j.drugalcdep.2012.08.012

Malet, L., Reynaud, M., Llorca, P.-M., Chakroun, N., Blanc, O., \& Falissard, B. (2009). Outcomes from primary care management of alcohol dependence in France. Journal of Substance Abuse Treatment, 36(4), 457-462. https://doi.org/10.1016/j.jsat.2008.08.006

Marceau, E. M., Lunn, J., Berry, J., Kelly, P. J., \& Solowij, N. (2016). The Montreal Cognitive Assessment (MoCA) is Sensitive to Head Injury and Cognitive Impairment in a Residential Alcohol and Other Drug Therapeutic Community. Journal of Substance Abuse Treatment, 66, 30-36. https://doi.org/10.1016/j.jsat.2016.03.002

Maremmani, A. G. I., Pani, P. P., Trogu, E., Vigna-Taglianti, F., Mathis, F., Diecidue, R., ... Maremmani, I. (2016). The impact of psychopathological subtypes on retention rate of patients with substance use disorder entering residential therapeutic community treatment. Annals of General Psychiatry, 15(1). https://doi.org/10.1186/s12991-0160119-x

Maremmani, A. G. I., Rovai, L., Bacciardi, S., Rugani, F., Pacini, M., Paolo Pani, P., ... Maremmani, I. (2013). The long-term outcomes of heroin dependent-treatmentresistant patients with bipolar 1 comorbidity after admission to enhanced methadone 
maintenance. Journal of Affective Disorders, 151(2), 582-589. https://doi.org/10.1016/j.jad.2013.06.054

McCaul, M. E., Svikis, D. S., \& Moore, R. D. (2001). Predictors of outpatient treatment retention: patient versus substance use characteristics. Drug and Alcohol Dependence, 62(1), 9-17. https://doi.org/10.1016/S0376-8716(00)00155-1

McEvoy, P. M., Stritzke, W. G. K., French, D. J., Lang, A. R., \& Ketterman, R. (2004). Comparison of three models of alcohol craving in young adults: a cross-validation. Addiction, 99(4), 482-497. https://doi.org/10.1111/j.1360-0443.2004.00714.x

McHugh, R. K., Murray, H. W., Hearon, B. A., Pratt, E. M., Pollack, M. H., Safren, S. A., \& Otto, M. W. (2013). Predictors of Dropout from Psychosocial Treatment in OpioidDependent Outpatients: Predictors of Treatment Dropout. The American Journal on Addictions, 22(1), 18-22. https://doi.org/10.1111/j.1521-0391.2013.00317.x

Meier, P. S., \& Barrowclough, C. (2009). Mental health problems: Are they or are they not a risk factor for dropout from drug treatment? A systematic review of the evidence. Drugs: Education, Prevention and Policy, 16, 7-38. https://doi.org/10.1080/09687630701741030

Miller, W. R., \& Tonigan, J. S. (1996). Assessing drinkers' motivation for change: The Stages of Change Readiness and Treatment Eagerness Scale (SOCRATES). Psychology of Addictive Behaviors, 10(2), 81-89. https://doi.org/10.1037/0893-164X.10.2.81

Montgomery, D. C. (2012). Design and Analysis of Experiments (8 edition). Hoboken, NJ: Wiley. Morgenstern, M., DiFranza, J. R., Wellman, R. J., Sargent, J. D., \& Hanewinkel, R. (2016). Relationship between early symptoms of alcohol craving and binge drinking 2.5 years 
later. Drug and Alcohol Dependence, 160, 183-189. https://doi.org/10.1016/j.drugalcdep.2016.01.008

Mulder, C. L., Koopmans, G. T., \& Hengeveld, M. W. (2005). Lack of motivation for treatment in emergency psychiatry patients. Social Psychiatry and Psychiatric Epidemiology, 40(6), 484-488. https://doi.org/10.1007/s00127-005-0913-2

Nasreddine, Z. S., Phillips, N. A., BÃ@dirian, V., Charbonneau, S., Whitehead, V., Collin, I., ... Chertkow, H. (2005). The Montreal Cognitive Assessment, MoCA: A Brief Screening Tool For Mild Cognitive Impairment: MOCA: A BRIEF SCREENING TOOL FOR MCl. Journal of the American Geriatrics Society, 53(4), 695-699. https://doi.org/10.1111/j.1532-5415.2005.53221.x

Observatoire Français des Drogues et des Toxicomanies. (2015). Drogues, chiffres clés (p. 19).

Palmer, R. S., Murphy, M. K., Piselli, A., \& Ball, S. A. (2009). Substance User Treatment Dropout from Client and Clinician Perspectives: A Pilot Study. Substance Use \& Misuse, 44(7), 1021-1038. https://doi.org/10.1080/10826080802495237

Perkins, K. S., Tharp, B. E., Ramsey, A. T., \& Patterson, D. (2016). Mapping the Evidence to Improve Retention Rates in Addiction Services. Journal of Social Work Practice in the Addictions, 16(3), 233-251. https://doi.org/10.1080/1533256X.2016.1200055

Picci, R. L., Oliva, F., Zuffranieri, M., Vizzuso, P., Ostacoli, L., Sodano, A. J., \& Furlan, P. M. (2014). Quality of life, alcohol detoxification and relapse: Is quality of life a predictor of relapse or only a secondary outcome measure? Quality of Life Research, 23(10), 2757-2767. https://doi.org/10.1007/s11136-014-0735-3 
Probst, C., Manthey, J., Martinez, A., \& Rehm, J. (2015). Alcohol use disorder severity and reported reasons not to seek treatment: a cross-sectional study in European primary care practices. Substance Abuse Treatment, Prevention, and Policy, 10, 32. https://doi.org/10.1186/s13011-015-0028-z

Prochaska, J. O., DiClemente, C. C., \& Norcross, J. C. (1992). In search of how people change: Applications to addictive behaviors. American Psychologist, 47(9), 1102-1114. https://doi.org/10.1037/0003-066X.47.9.1102

Rapp, R. C., Xu, J., Carr, C. A., Lane, D. T., Wang, J., \& Carlson, R. (2006). Treatment barriers identified by substance abusers assessed at a centralized intake unit. Journal of $\begin{array}{lll}\text { Substance } \quad \text { Abuse } & \text { 227-235. }\end{array}$ https://doi.org/10.1016/j.jsat.2006.01.002

Ray, L. A., Hutchison, K. E., \& Bryan, A. (2006). Psychosocial Predictors of Treatment Outcome, Dropout, and Change Processes in a Pharmacological Clinical Trial for Alcohol Dependence: Addictive Disorders \& Their Treatment, 5(4), 179-190. https://doi.org/10.1097/01.adt.0000210701.63165.5a

Redko, C., Rapp, R. C., \& Carlson, R. G. (2006). Waiting time as a barrier to treatment entry: Perceptions of substance users. Journal of Drug Issues, 36(4), 831-852. https://doi.org/10.1177/002204260603600404

Rehm, J., Taylor, B., Roerecke, M., \& Patra, J. (2007). Alcohol consumption and alcoholattributable burden of disease in Switzerland, 2002. International Journal of Public Health, 52(6), 383-392. https://doi.org/10.1007/s00038-007-7010-0

Rice, S. L., Hagler, K. J., \& Tonigan, J. S. (2014). Longitudinal Trajectories of Readiness to Change: Alcohol Use and Help-Seeking Behavior. Journal of Studies on Alcohol and Drugs, 75(3), 486-495. https://doi.org/10.15288/jsad.2014.75.486 
Roncero, C., Ortega, L., Perez-Pazos, J., Lligona, A., Abad, A. C., Gual, A., ... Daigre, C. (2015). Psychiatric Comorbidity in Treatment-Seeking Alcohol Dependence Patients With and Without ADHD. Journal of Attention Disorders. https://doi.org/10.1177/1087054715598841

Roncero, C., Rodríguez-Cintas, L., Barral, C., Fuste, G., Daigre, C., A Ramos-Quiroga, J., \& Casas, M. (2012). Treatment adherence to treatment in substance users referred from Psychiatric Emergency service to outpatient treatment. Actas españolas de psiquiatría, $40(2), 63-69$.

Santa Ana, E. J., Wulfert, E., \& Nietert, P. J. (2007). Efficacy of group motivational interviewing (GMI) for psychiatric inpatients with chemical dependence. Journal of Consulting and Clinical Psychology, 75(5), 816-822. https://doi.org/10.1037/0022-006X.75.5.816

Saunders, S. M., Zygowicz, K. M., \& D’Angelo, B. R. (2006). Person-related and treatmentrelated barriers to alcohol treatment. Journal of Substance Abuse Treatment, 30(3), 261-270. https://doi.org/doi:10.1016/j.jsat.2006.01.003

Schlauch, R. C., Christensen, R. L., Derrick, J. L., Crane, C. A., \& Collins, R. L. (2015). Individual Differences in Approach and Avoidance Inclinations Moderate the Effect of SelfControl Depletion on Ad-Lib Drinking. Alcoholism: Clinical and Experimental Research, 39(12), 2480-2488. https://doi.org/10.1111/acer.12915

Schlauch, R. C., Levitt, A., Bradizza, C. M., Stasiewicz, P. R., Lucke, J. F., Maisto, S. A., ... Connors, G. J. (2013). Alcohol craving in patients diagnosed with a severe mental illness and alcohol use disorder: Bidirectional relationships between approach and avoidance inclinations and drinking. Journal of Consulting and Clinical Psychology, 81(6), 10871099. https://doi.org/10.1037/a0033914 
Skule, C., Berge, T., Eilertsen, E., Ulleberg, P., Dallavara Lending, H., Egeland, J., \& Landr?, N. I. (2017). Levels of alcohol use and depression severity as predictors of missed therapy sessions in cognitive behavioural psycho-educational group treatment for depression. $\begin{array}{llll}\text { Addiction } \quad \text { Research } & \text { 25(1), } & \text { 11-16. }\end{array}$ https://doi.org/10.3109/16066359.2016.1173683

Smith, D., Harvey, P., Battersby, M., Pols, R., Oakes, J., \& Baigent, M. (2010). Treatment outcomes and predictors of drop out for problem gamblers in South Australia: a cohort study. Australian and New Zealand Journal of Psychiatry, 44(10), 911-920. https://doi.org/10.3109/00048674.2010.493502

Spruyt, A., De Houwer, J., Tibboel, H., Verschuere, B., Crombez, G., Verbanck, P., ... Noël, X. (2013). On the predictive validity of automatically activated approach/avoidance tendencies in abstaining alcohol-dependent patients. Drug and Alcohol Dependence, 127(1-3), 81-86. https://doi.org/10.1016/j.drugalcdep.2012.06.019

Stevens, L., Betanzos-Espinosa, P., Crunelle, C. L., Vergara-Moragues, E., Roeyers, H., Lozano, O., ... Pérez-García, M. (2013). Disadvantageous Decision-Making as a Predictor of Drop-Out among Cocaine-Dependent Individuals in Long-Term Residential Treatment. Frontiers in Psychiatry, 4. https://doi.org/10.3389/fpsyt.2013.00149

Tiffany, S. T., \& Wray, J. M. (2012). The clinical significance of drug craving: Tiffany \&amp; Wray. Annals of the New York Academy of Sciences, 1248(1), 1-17. https://doi.org/10.1111/j.1749-6632.2011.06298.x

Vafaeinasab, M. R., Farahzadi, M. H., Razaghi, O. M., Fallahzadeh, R. A., Lotfi, M. H., \& Akhondzadeh, S. (2015). Investigation of Affecting Factors on Persistence in the Treatment of Patients under Methadone Maintenance Therapy in Addiction Therapy 
Centers, Yazd-Iran. Health, 606-616. https://doi.org/10.4236/health.2015.75072

van Emmerik-van Oortmerssen, K., van de Glind, G., Koeter, M. W. J., Allsop, S., Auriacombe, M., Barta, C., ... Schoevers, R. A. (2014). Psychiatric comorbidity in treatment-seeking substance use disorder patients with and without attention deficit hyperactivity disorder: results of the IASP study: Comorbidity in SUD patients with ADHD. Addiction, 109(2), 262-272. https://doi.org/10.1111/add.12370

Vuoristo-Myllys, S., Lahti, J., Alho, H., \& Julkunen, J. (2013). Predictors of Dropout in an Outpatient Treatment for Problem Drinkers Including Cognitive-Behavioral Therapy and the Opioid Antagonist Naltrexone. Journal of Studies on Alcohol and Drugs, 74(6), 894-901. https://doi.org/10.15288/jsad.2013.74.894

Wagner, V., Bertrand, K., Flores-Aranda, J., Acier, D., Brunelle, N., Landry, M., \& Brochu, S. (2017). Initiation of Addiction Treatment and Access to Services: Young Adults' Accounts of Their Help-Seeking Experiences. Qualitative Health Research, 27(11), 1614 -1627. https://doi.org/10.1177/1049732316679372

Ware, J. E., \& Sherbourne, C. D. (1992). The MOS 36-item short-form health survey (SF-36). I. Conceptual framework and item selection. Medical Care, 30(6), 473-483.

Witkiewitz, K. (2011). Predictors of heavy drinking during and following treatment. Psychology of Addictive Behaviors, 25(3), 426-438. https://doi.org/10.1037/a0022889

Zimbardo, P. G., \& Boyd, J. N. (1999). Putting time in perspective: A valid, reliable individualdifferences metric. Journal of Personality and Social Psychology, 77(6), 1271-1288. https://doi.org/10.1037/0022-3514.77.6.1271 
Table 1

Sociodemographic characteristics of the sample at the entry in treatment

\begin{tabular}{|c|c|c|}
\hline Variables & $n$ & $\%$ \\
\hline \multicolumn{3}{|l|}{ Gender } \\
\hline Man & 111 & 74.0 \\
\hline Woman & 39 & 26.0 \\
\hline \multicolumn{3}{|l|}{ Education } \\
\hline 9 years of less & 21 & 14.0 \\
\hline 11 years (secondary professional education) & 52 & 34.7 \\
\hline 12 years (secondary education) & 35 & 23.3 \\
\hline 14 years & 23 & 15.3 \\
\hline$>14$ years & 19 & 12.7 \\
\hline \multicolumn{3}{|l|}{ Professional status } \\
\hline Permanent contract or equal & 85 & 56.7 \\
\hline Unemployed and other inactive & 51 & 34.0 \\
\hline Retired & 14 & 9.3 \\
\hline \multicolumn{3}{|l|}{ Socioprofessional category } \\
\hline Craftsman, shopkeeper & 12 & 8.0 \\
\hline Executive, liberal profession & 28 & 18.7 \\
\hline Intermediate profession & 10 & 6.7 \\
\hline Employee & 54 & 36.0 \\
\hline Factory worker & 46 & 30.7 \\
\hline \multicolumn{3}{|l|}{ Main financial resources } \\
\hline Salary & 87 & 58.0 \\
\hline Retirement pension & 14 & 9.3 \\
\hline Social aids, disability pensions & 25 & 16.7 \\
\hline Unemployment benefits & 24 & 16.0 \\
\hline \multicolumn{3}{|l|}{ Housing type } \\
\hline $\begin{array}{l}\text { Long-lasting (independent, with relatives, } \\
\text { institutionalization) }\end{array}$ & 138 & 92.0 \\
\hline Temporary (with relatives, institutionalization, other) & 12 & 8.0 \\
\hline \multicolumn{3}{|l|}{ Housing arrangement } \\
\hline Alone & 56 & 37.3 \\
\hline With family (parents, children, spouse) & 83 & 55.3 \\
\hline \multirow[t]{2}{*}{ Other situations } & 11 & 7.3 \\
\hline & $S D$ & Min $\quad \operatorname{Max}$ \\
\hline Age & 45.01 & 19 \\
\hline
\end{tabular}

Note. $N=150$. 
Table 2

Comparisons between dropouts and patients remaining in care according to sociodemographic variables

\begin{tabular}{|c|c|c|c|c|c|}
\hline & \multicolumn{4}{|c|}{ Follow-up status } & \multirow[b]{3}{*}{$\chi^{2}$} \\
\hline & \multicolumn{2}{|c|}{$\begin{array}{c}\text { Remaining in } \\
\text { care } \\
\left(N_{1}=81\right)\end{array}$} & \multicolumn{2}{|c|}{$\begin{array}{l}\text { Dropout } \\
\left(N_{2}=69\right)\end{array}$} & \\
\hline & $n$ & $\%$ & $n$ & $\%$ & \\
\hline Gender & & & & & \multirow[t]{3}{*}{ ns } \\
\hline Man & 58 & 71.6 & 53 & 76.8 & \\
\hline Woman & 23 & 28.4 & 16 & 23.2 & \\
\hline \multicolumn{5}{|l|}{ Education } & \multirow[t]{6}{*}{ ns } \\
\hline 9 years of less & 8 & 9.9 & 13 & 18.8 & \\
\hline $\begin{array}{l}11 \text { years (secondary professional } \\
\text { education) }\end{array}$ & 25 & 30.9 & 27 & 39.1 & \\
\hline 12 years (secondary education) & 22 & 27.2 & 13 & 18.8 & \\
\hline 14 years & 13 & 16.0 & 10 & 14.5 & \\
\hline$>14$ years & 13 & 16.0 & 6 & 8.7 & \\
\hline \multicolumn{5}{|l|}{ Professional status } & \multirow[t]{4}{*}{ ns } \\
\hline Permanent contract or equal & 47 & 58.0 & 38 & 55.1 & \\
\hline Unemployed and other inactive & 26 & 32.1 & 25 & 36.2 & \\
\hline Retired & 8 & 9.9 & 6 & 8.7 & \\
\hline \multicolumn{5}{|l|}{ Socioprofessional category } & \multirow[t]{6}{*}{ ns } \\
\hline Craftsman, shopkeeper & 4 & 4.9 & 8 & 11.6 & \\
\hline Executive, liberal profession & 14 & 17.3 & 14 & 20.3 & \\
\hline Intermediate profession & 8 & 9.9 & 2 & 2.9 & \\
\hline Employee & 31 & 38.3 & 23 & 33.3 & \\
\hline Factory workers & 24 & 29.6 & 22 & 31.9 & \\
\hline \multicolumn{5}{|l|}{ Main financial resources } & \multirow[t]{5}{*}{ ns } \\
\hline Salary & 48 & 59.3 & 39 & 56.5 & \\
\hline Retirement pension & 8 & 9.9 & 6 & 8.7 & \\
\hline Social aids, disability pensions & 16 & 19.8 & 9 & 13.0 & \\
\hline Unemployment benefits & 9 & 11.1 & 15 & 21.7 & \\
\hline \multicolumn{5}{|l|}{ Housing type } & \multirow[t]{3}{*}{ ns } \\
\hline $\begin{array}{l}\text { Long-lasting (independent, with } \\
\text { relatives, institutionalization) }\end{array}$ & 75 & 92.6 & 63 & 91.3 & \\
\hline $\begin{array}{l}\text { Temporary } \quad \text { (with } \\
\text { institutionalization, other) }\end{array}$ & 6 & 7.4 & 6 & 8.7 & \\
\hline \multicolumn{5}{|l|}{ Housing arrangement } & \multirow[t]{4}{*}{ ns } \\
\hline Alone & 31 & 38.4 & 25 & 36.2 & \\
\hline With family (parents, children, spouse) & 42 & 51.9 & 41 & 59.4 & \\
\hline \multirow[t]{2}{*}{ Other situations } & 8 & 9.9 & 3 & 4.3 & \\
\hline & $M$ & $S D$ & $M$ & $S D$ & $\begin{array}{l}\text { Tukey- } \\
\text { Kramer }\end{array}$ \\
\hline Age & 45.95 & 10.92 & 43.90 & 11.52 & ns \\
\hline
\end{tabular}

Note. $N=150$. Group comparisons with $\chi^{2}$ test or Tukey-Kramer method.

$* * * p<.001 . * * p<.01$. * $p<.05$. ns for $p>.05$. 
Table 3

Comparisons between dropouts and patients remaining in care according to substance-related variables

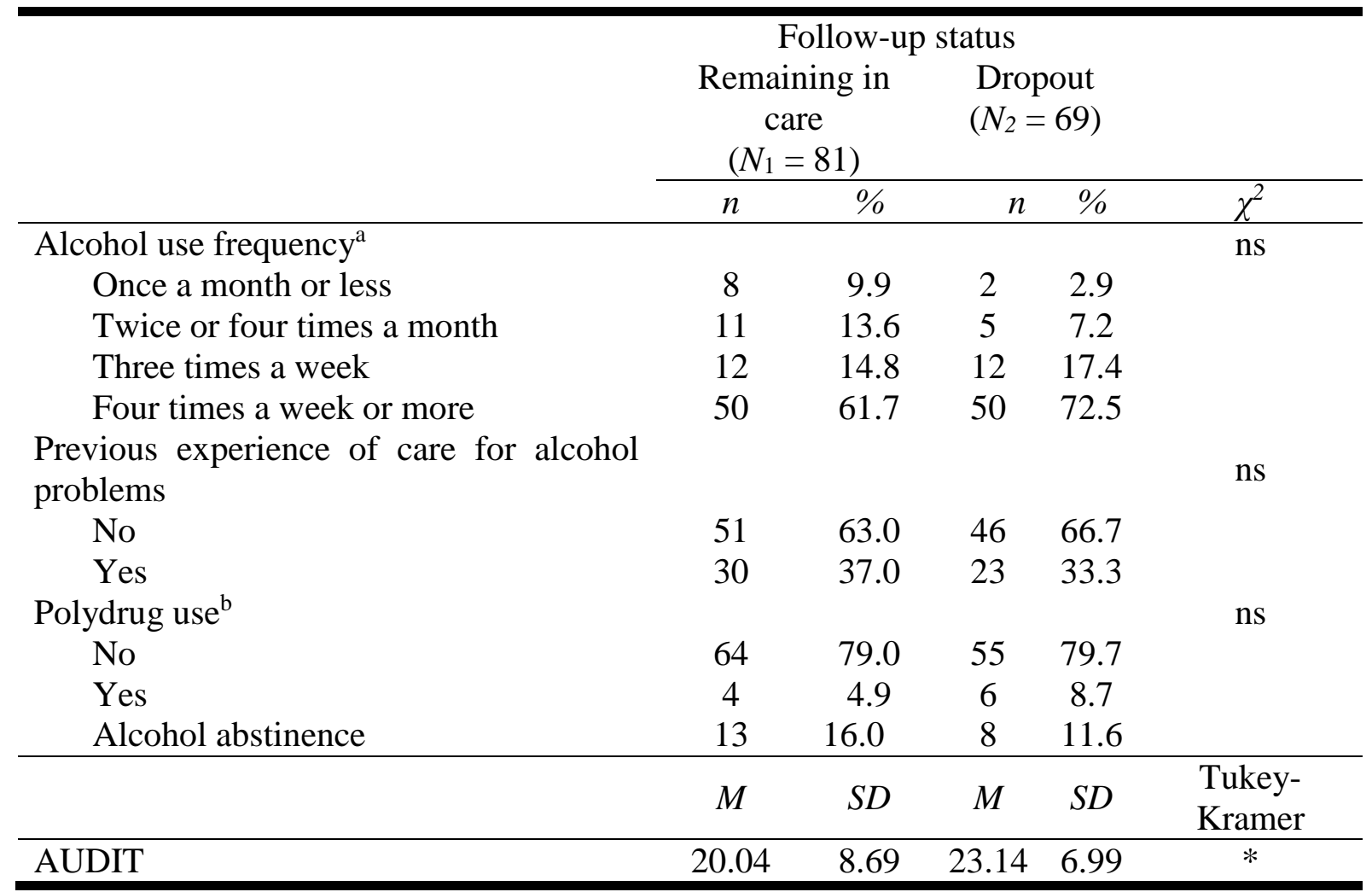

Note. $N=150$. Group comparisons with $\chi^{2}$ test or Tukey-Kramer method. ${ }^{\text {a }}$ During the last 12 months. ${ }^{\mathrm{b}}$ Any other substance or behavioral trouble, excepting tobacco.

$* * * p<.001 . * * p<.01 . * p<.05$. ns for $p>.05$. 
Table 4

Comparisons between dropouts and patients remaining in care according to treatment-related variables

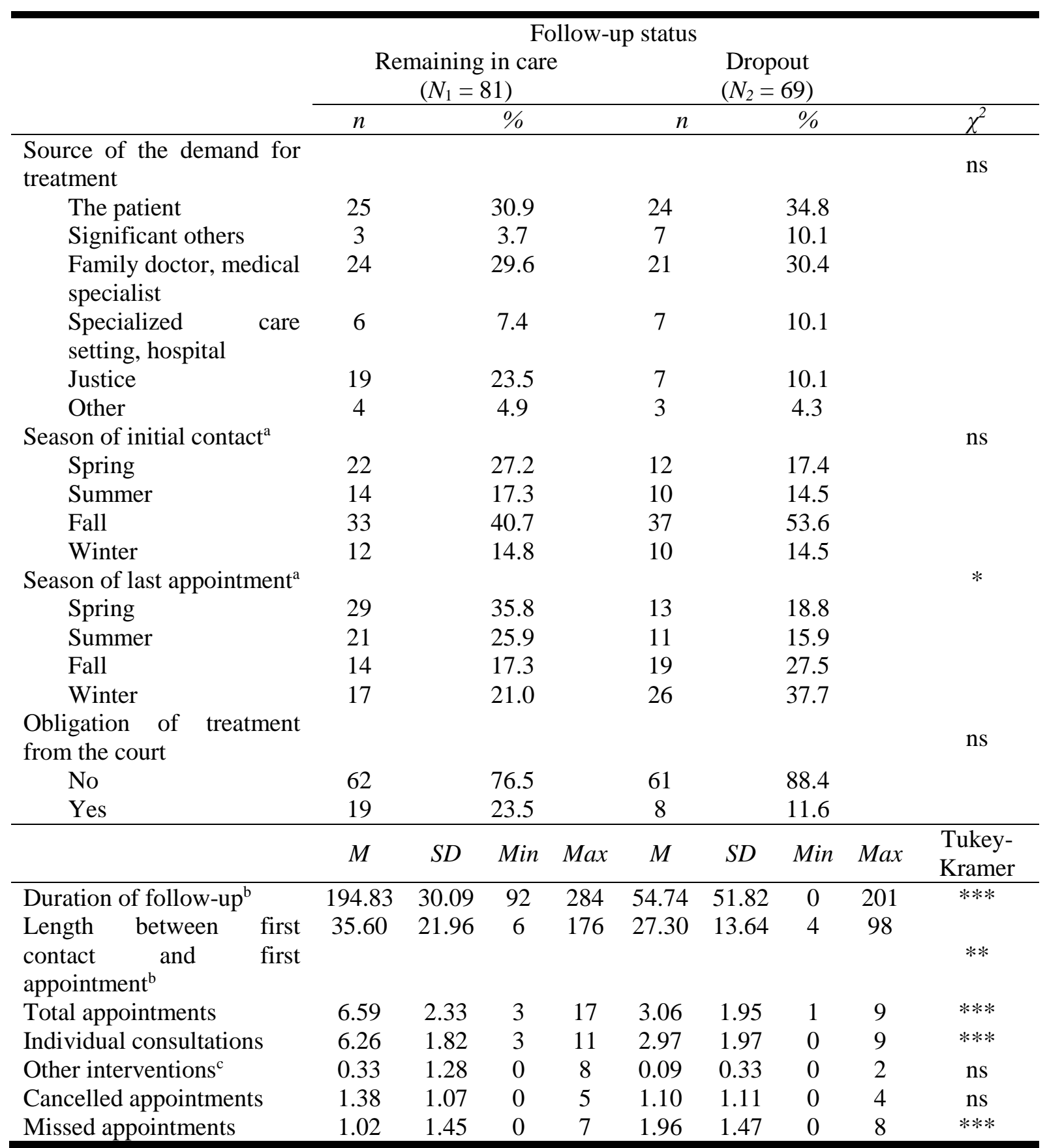

Note. $N=150$. Group comparisons with $\chi^{2}$ test or Tukey-Kramer method. ${ }^{\text {a }}$ Spring season includes March, April, May, Summer season, June, July, August, Fall season, September, October, November and Winter, December, January, February. ${ }^{\mathrm{b}}$ Duration in days. ${ }^{\mathrm{c}}$ Includes family and marital consultations, recreational workshops and support or relaxation groups.

$* * * p<.001 . * * p<.01 . * p<.05$. ns for $p>.05$. 
Table 5

Comparisons between dropouts and patients remaining in care regarding other psychometric variables

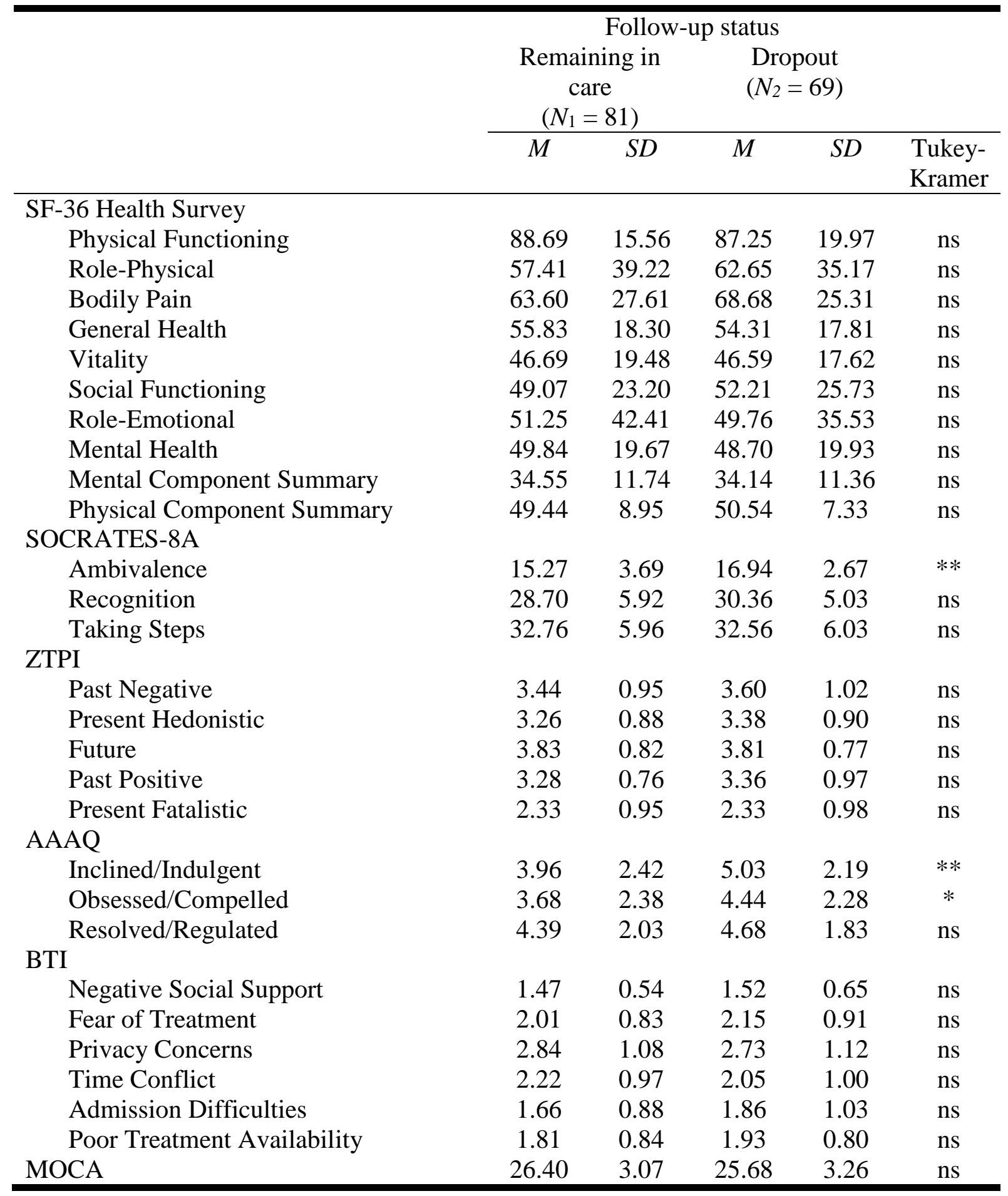

Note. $N=150$. Group comparisons with Tukey-Kramer method.

$* * * p<.001$. ** $p<.01$. * $p<.05$. ns for $p>.05$. 